\title{
MERCURY RETENTION BY FLY ASHES FROM OXY-FUEL PROCESSES
}

Nuria Fernández-Miranda, Marta Rumayor, M. Antonia Lopez-Anton*, Mercedes DíazSomoano, M. Rosa Martínez-Tarazona

Instituto Nacional del Carbón (CSIC), Francisco Pintado Fe, 26, 33011, Oviedo, Spain

*Corresponding author:

Phone: +34 985119090

Fax: +34 985297662

Email: marian@incar.csic.es 


\begin{abstract}
The objective of this study is to determine the mechanism of mercury retention in fly ashes, the main solid waste from coal combustion power plants, and to evaluate the interactions between the type of mercury and fly ashes. The work was based on the results of mercury speciation in the gas and the solid fly ash before and after mercury retention. The identification of the mercury species in the gas was performed using previously validated methods but the speciation of the mercury retained in the fly ashes was carried out using a mercury temperature programmed desorption technique (HgTPD) still under development. The fly ashes were sampled from conventional coal combustion in air and oxy-combustion power plants. The main mercury species identified in the raw fly ashes and after they were subjected to an oxy-combustion atmosphere were mercury bound to organic matter and $\mathrm{HgS}$, the ratio of these species depending on the characteristics of the ashes. The results obtained indicate that fly ashes are the route of mercury oxidation in an oxy-combustion atmosphere, although they hardly retain any mercury unless the unburned carbon content is high. HgTPD analysis shows that the main mechanism for mercury retention in the fly ashes is via the carbon matter.
\end{abstract}

Keywords: mercury; fly ash; oxy-fuel combustion 


\section{Introduction.}

The contribution of coal combustion to toxic mercury emissions to the environment and the problems that these emissions represent are well known, as are the enormous efforts being made to reduce such emissions. Government organizations, researchers and industry are all involved in this task. ${ }^{1}$ Several methods are already being investigated and, in some cases, implemented to prevent mercury emissions from coal combustion. To achieve this goal, it is necessary to have knowledge of the behavior of mercury along the process and of the interactions of this element with the sub-products produced in the power plant, such as fly ashes and gypsums. If the mercury species in combustion by-products can be determined, the risk posed by these solids when they are reused or disposed of can be predicted. Mercury present in coal evaporates as elemental mercury $\left(\mathrm{Hg}^{0}\right)$ during combustion but it is partially transformed into oxidized species $\left(\mathrm{Hg}^{2+}\right)$ as the flue gas cools. These species may react with the sub-products and be retained on the solids in different proportions and then be partially removed in the gas cleaning system. When interacting with the fly ashes, the main solid waste from coal combustion power plants, some mercury species may be adsorbed. As a consequence, a proportion of mercury can be captured in the particle control devices, resulting in a reduction of mercury emissions from the stack. However, mercury retention in fly ashes varies considerably depending on the type of coal and power plant. ${ }^{2-4}$ The need to understand mercury retention mechanisms in fly ashes and to identify the variables that modify retention efficiency has led to a wide body of research in this field that calls for an extensive review. Although such a review is outside the scope of this paper, a summary of the most important conclusions of these research works can be attempted.

No clear mechanism that explains how the different mercury species are retained in fly ashes has been satisfactorily established probably because the retention of mercury 
in fly ash occurs via more than one mechanism depending on the characteristics of the ashes and process conditions. ${ }^{5-9}$ However, the results obtained so far permit some generalizations that might be useful for industrial processes:

1) Regardless of the ash composition it can be stated that mercury is more easily retained in ashes with a high content in unburned coal particles. ${ }^{10-17}$ This affirmation has been verified in a number of works, although the precise mechanism via which sorption on carbon takes place has still not been clearly established.

2) If chlorides are present on the carbon surface, they play a significant role in the mechanism of oxidation/retention of mercury. ${ }^{18-19}$ However the reason for this is even more difficult to explain than the effect of unburned particles.

3) Since mercury retention depends on the temperature of the flue-gas at the point of collection $^{2}$ and the retention is greater, the longer the contact time between the gas and the ashes, mercury is more efficiently captured in power plants that are equipped with bag-houses rather than electrostatic precipitators. ${ }^{20}$

Apart from the three factors just mentioned, other considerations such as i) the role of the carbon structure on mercury adsorption and oxidation, ${ }^{4,13,21}$ ii) the possibility that elemental mercury $\left(\mathrm{Hg}^{0}\right)$ will be adsorbed onto the porous surface, ${ }^{4}$ iii) the effect of mineral matter as a possible catalyst, ${ }^{14,22-23}$ and iv) the mechanism responsible for chlorine-mercury reaction on the carbonaceous fraction of fly ashes ${ }^{24-25}$ still need to be addressed.

The objective of the present work is to help clarify some of the above mentioned points, focusing on the interaction between mercury species and fly ashes obtained from oxy-fuel combustion plants and coal combustion in air with two main objectives in mind i) to identify the differences that can be expected to result from these interactions in the relatively new oxy-combustion processes designed for $\mathrm{CO}_{2}$ capture and storage 
and conventional air combustion and ii) to obtain new data that will improve our understanding of the mechanisms via which different species of mercury are retained in ashes of different characteristics. In addition, the knowledge of mercury speciation in fly ashes is important for evaluating the risks in the reutilization or disposal of wastes. The discussion of the results is based on the mercury speciation in the gas and the solid fly ash before and after they have been subjected to a gas atmosphere containing mercury. To identify mercury species in the solids a temperature programmed desorption method (HgTPD) has been used.

\section{Materials and methods}

\subsection{Fly ash samples.}

Fly ashes were obtained from 3 fluidized bed combustion plants. Plants 1 and 2 operated in oxy-combustion mode, whereas plant 3 functioned in conventional air combustion mode. The main characteristics of the power plants and the combustibles used are presented in Table 1 . The three fly ash samples (CTCIU) from the $30 \mathrm{MW}$ oxyfuel power plant (FBC_1) were taken from different sampling points. CTCIU-A and CTCIU-A/P were collected from the inlet pipe of the fly ash storage bin, while the fly ash labelled CTCIU-R-A/P was taken from the recirculation bin to the boiler. The CTCIE fly ash was obtained from the dust cyclone at the outlet of the flue gas pipe after the boiler in a $100 \mathrm{~kW}$ pilot plant (FBC_2). The fly ash CTP was sampled from the electrostatic precipitator of a 50 MW power plant (FBC_3) operating in fluidized bed combustion in air.

The chemical composition of the fly ashes was determined by X-Ray fluorescence (XRF) using the ASTM D 4326 standard method. The chlorine content was analyzed by ion chromatography. The concentration of mercury in the raw fly ash samples was 
determined using an advanced mercury analyser (AMA 254). The unburned carbon particle content was calculated as loss of ignition (LOI) by combustion of the organic matter at $815{ }^{\circ} \mathrm{C}$. The Brunauer-Emmett-Teller (BET) surface area was measured by volumetric adsorption of nitrogen at $77 \mathrm{~K}$.

\subsection{Experimental device for mercury retention}

The tests for evaluating the interactions of mercury with the fly ashes were carried out in an experimental laboratory scale device illustrated in Figure 1. The device consisted of: (1) a gas blending station equipped with mass flow controllers to prepare the gas composition that simulates a typical oxy-combustion atmosphere $\left(64 \% \mathrm{CO}_{2}\right.$, $20 \% \mathrm{~N}_{2}, 12 \% \mathrm{H}_{2} \mathrm{O}, 4 \% \mathrm{O}_{2}, 1000$ ppm SO 2,1000 ppm NO, 100 ppm $\mathrm{NO}_{2}$ and 25 ppm $\mathrm{HCl}$ ), (2) a calibrated permeation tube (VICI Metronic) placed inside a glass "U" tube inmersed in a water bath to obtain $100 \mu \mathrm{g} \mathrm{m}^{-3} \mathrm{of} \mathrm{Hg}^{0}$ in gas phase (3) a glass reactor (length, $500 \mathrm{~mm}$; diameter, $25 \mathrm{~mm}$ ) where a sorbent bed is placed. The sorbent bed was prepared by mixing $0.05 \mathrm{~g}$ of fly ash with $0.65 \mathrm{~g}$ of sand in order to avoid an excess of pressure in the system. The reactor and the gases were kept at $150^{\circ} \mathrm{C}$. The total volume of the flow gases that passed through the sorbent was $0.5 \mathrm{~L} \cdot \mathrm{min}^{-1}$ and (4) a continuous mercury analyser (VM 3000) to monitor the $\mathrm{Hg}^{0}$. A Dowex ${ }^{\circledR} 1 \mathrm{x} 8$ ion exchanger resin was used to determine the oxidized mercury $\left(\mathrm{Hg}^{2+}\right) \cdot{ }^{26-27}$ The resin was placed after the point of condensation of the water vapour from the gas stream and before the VM 3000 analyser (Figure 1) in order that the total mercury concentration could be balanced. The total amount of $\mathrm{Hg}$ retained in the fly ashes and the $\mathrm{Hg}^{2+}$ captured in the resin and in the condensed water was analyzed using AMA equipment. The duration of the mercury retention experiments was the time needed for the samples to reach their maximum retention capacity. 


\subsection{Experimental device for mercury speciation}

A thermal programmed desorption (HgTPD) procedure previously optimized by the authors $^{28}$ was employed to identify the mercury compounds in the raw fly ash samples and after the mercury retention experiments. The equipment consists of a continuous mercury analyser (RA-915) coupled to a furnace (PYRO-915) from Lumex. The PYRO-915 furnace consists of a first chamber where the fly ash samples are pyrolyzed to release the mercury compounds and a second chamber where the mercury species are reduced to elemental mercury. The heating rate chosen was $50^{\circ} \mathrm{C} \cdot \mathrm{min}^{-1}$ from room temperature to $750{ }^{\circ} \mathrm{C}$. The temperature of the second chamber was kept at $800{ }^{\circ} \mathrm{C}$. The mercury species were characterized according to the temperature range in which they were released. For this purpose, the desorption profiles of the samples were compared with reference desorption profiles of previously analyzed pure mercury compounds. ${ }^{28}$

The HgTPD results were compared with those obtained by the method based on sequential extraction. This procedure, as explained previously, ${ }^{29}$ is a simplification of the US Environmental Protection Agency Method 3200 (US EPA Method 3200). The method consists of three sequential extraction steps that split the mercury species into three fractions as a function of the solubility of each species in different solutions: F1 (mobile $\mathrm{Hg}$ (inorganic and organic $\mathrm{Hg}$ )), F2 (semi-mobile $\mathrm{Hg}$ (mainly $\mathrm{Hg}^{0}, \mathrm{Hg}^{2+}$ complexes)) and F3 (non-mobile Hg (mainly HgS)).

\section{Results and discussion}

\subsection{Mercury in the raw fly ashes}

The chemical composition, mercury and chorine content, unburned carbon percentage (LOI) and BET surface area of the raw fly ash samples (ashes from the 
combustion plants before they are subjected to experiments), are presented in Table 2 . The CTCIU fly ashes from oxy-combustion show similar characteristics regardless of whether the fuel is anthracite or an anthracite/petcoke blend and whatever the sampling point. These fly ashes have the highest contents in calcium (18-25\% expressed as oxide) and sulfur (9-10\% expressed as $\mathrm{SO}_{3}$ ). A comparison of the fly ashes from oxycombustion and from combustion in air shows that the most significant difference is the high content in chlorine and LOI in the case of the oxy-combustion fly ashes. This is not a consequence of the combustion process itself but a result of the particular characteristics of the plants where the fly ashes were sampled. What is especially remarkable is that the CTCIE fly ash has a chlorine content as high as $\sim 0.6 \%$, a LOI percentage of $28 \%$ and a surface area of $39 \mathrm{~m}^{2} / \mathrm{g}$ (Table 2). Such characteristics are bound to have a considerable effect on mercury adsorption.

The mercury desorption profiles obtained by HgTPD (Figure 2a) for the raw fly ashes show that mercury is mainly released between 100 and $400^{\circ} \mathrm{C}$. In this temperature range the mercury species that are most likely to be found are $\mathrm{HgCl}_{2}, \mathrm{HgS}$ black, $\mathrm{HgS}$ red and $\mathrm{Hg}$ bound to organic matter (Hg-OM) (Figure 2b) whose characteristic peak desorption temperatures are $138 \pm 4,190 \pm 11,305 \pm 12$ and $220 \pm 5$, respectively.

Two important factors must be borne in mind in the analysis by HgTPD: 1) there are two different HgS crystalline structures: HgS black or metacinnabar and HgS red or cinnabar and these decompose at different temperatures ${ }^{30}$ and 2) a drawback to the HgTPD method might be the difficulty in finding a mercury standard which represents the binding of mercury to organic matter in this type of sorbent. To overcome this obstacle, a mercury reference species was prepared from humic acid. ${ }^{31}$ Humic acids contain $\mathrm{COOH}, \mathrm{OH}$ and $\mathrm{CO}$ groups and, although these functionalities can vary in 
different carbon materials, it has been observed that they are compatible with the organic matter bound to mercury in different carbon materials. ${ }^{32-33}$

A previous study carried out by $\operatorname{HgTPD}^{29}$ with different types of solid samples demonstrated that HgS and Hg-OM were the main mercury species present in CTP fly ash. The CTP desorption profile also showed a peak at $630^{\circ} \mathrm{C}$ that corresponds to $\mathrm{HgSO}_{4}{ }^{28,29}$ However, in the fly ashes from oxy-combustion with a high LOI content, the main species identified correspond to mercury bound to organic matter (Hg-OM) (Figure 2a). In addition to the Hg-OM species, HgS red may be present in low concentrations in the CTCIU fly ashes which show a small shoulder in the desorption profile at around $300^{\circ} \mathrm{C}$. $\mathrm{HgS}$ black with a peak at $190^{\circ} \mathrm{C}$ may also be present in these fly ashes.

To clarify these results a series of extractions was carried out using the sequential extraction method ${ }^{29}$ and the samples were then analysed by HgTPD. The presence of mercury bound to organic matter in CTP, CTCIU and CTCIE was corroborated by the presence of 53.5, 85.0 and $95.1 \%$, respectively, of mercury in the semi-mobile fraction (F2) corresponding mainly to $\mathrm{Hg}^{2+}$ complexes. When the remaining fraction (F3) corresponding to non-mobile mercury (mainly HgS) was analysed by HgTPD (Figure 3), the peak corresponding to Hg-OM disappeared confirming that the peak at around $200^{\circ} \mathrm{C}$ corresponds to $\mathrm{Hg}-\mathrm{OM}$ and not $\mathrm{HgS}$ black which desorbs at a similar temperature. The occurrence of $\mathrm{HgS}$ red in CTP identified by the peak at $300^{\circ} \mathrm{C}$ was also confirmed by the presence of $47.3 \%$ of mercury in the non-mobile fraction (F3). ${ }^{29}$ The analysis by HgTPD of the sample after total extraction, labelled F4, does not show a mercury signal confirming that HgS red is the other species mainly present in CTP (Figure 3b). The results of this study by HgTPD confirm beyond all doubt that it is the 
carbon particles that play the most important role in the interactions between mercury and fly ashes in both coal combustion processes.

\subsection{Mercury in post-retention fly ashes}

The fly ashes were subjected to synthetic atmospheres containing mercury in a laboratory scale device (Figure 1). The first series of mercury retention experiments was carried out in a $\mathrm{N}_{2}$ atmosphere to evaluate the interaction between $\mathrm{Hg}^{0}$ and the fly ash in an inert atmosphere. Figure 4 shows the percentages of mercury retained in the fly ashes (Hgp), the total amount of oxidized mercury $\left(\mathrm{Hg}^{2+}\right)$ in the gas stream resulting from homogeneous (gas-gas interaction) and heterogeneous (gas-sorbent interaction) oxidation and the mercury that remains as elemental mercury $\left(\mathrm{Hg}^{0}(\mathrm{~g})\right)$. $\mathrm{The}^{2+} \mathrm{g}^{2+}$ at the outlet of the reactor was determined by capturing it in an ion exchanger resin suitable for the selective extraction of $\mathrm{Hg}^{2+}$ species. A resin bed was placed after the reactor for each mercury experiment which was then analyzed by means of the AMA equipment.

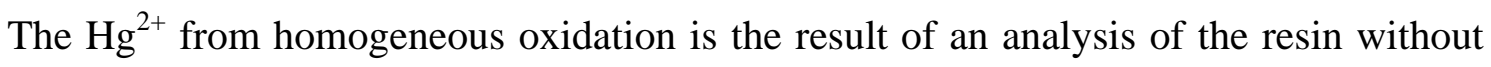
the sorbent, whereas the $\mathrm{Hg}^{2+}$ from heterogeneous oxidation is the $\mathrm{Hg}^{2+}$ retained in the resin after the reactor with the sorbent. No homogeneous oxidation occurs in the $\mathrm{N}_{2}$ atmosphere. Therefore, all the $\mathrm{Hg}^{2+}$ generated in gas phase must be as a result of heterogeneous oxidation. A percentage ranging from 2 to $4 \%$ of $\mathrm{Hg}^{2+}$ was observed in all the fly ashes. Most of the mercury remained in gas phase as $\mathrm{Hg}^{0}$, reflecting the low mercury retention capacity of the fly ashes. However the CTCIE fly ash deserves to be looked at more closely. Although the capture of $\mathrm{Hg}^{0}$ in fly ashes is thought to occur only in small amounts compared to that of $\mathrm{Hg}^{2+}$ formed during coal combustion and/or as a consequence of the oxidation of $\mathrm{Hg}^{0}$ by the carbon particles, ${ }^{34}$ the adsorption of $\mathrm{Hg}^{0}$ in the CTCIE cannot be ruled out. The CTCIE fly ash shows a mercury retention 
capacity of almost 25\%, which is a high level of retention for an inert atmosphere. This fly ash besides having the highest chlorine content, has the highest BET surface area and unburned carbon content (Table 2). In fact, a correlation can be observed between Hgp and surface area (Figure 5a) and LOI (Figure 5b). Therefore, the possibility that $\mathrm{Hg}^{0}$ is physisorbed onto the carbon surface of the fly ash when the only gas present in the atmosphere is $\mathrm{N}_{2}$ needs to be considered as likely. It is worth pointing out that when CTCIE was analysed by HgTPD an intensive peak corresponding to mercury bound to organic matter (Hg-OM) was observed, suggesting that mercury oxidation is promoted by the carbon matter itself. The HgTPD signal corresponding to the sample after the extraction of F2 (corresponding to $\mathrm{Hg}^{2+}$ complexes) decreased sharply confirming that mercury was bound to organic matter.

In a simulated flue gas of oxy-combustion, the distribution of the mercury species completely changes (Figure 6). A percentage of $30 \%$ of $\mathrm{Hg}^{2+}$ resulting from homogeneous oxidation $\left(\mathrm{Hg}^{2+} \mathrm{HO}\right)$ is obtained in this oxy-combustion atmosphere, ${ }^{27}$ although heterogeneous oxidation also takes place. The heterogeneous oxidation of mercury $\left(\mathrm{Hg}^{2+} \mathrm{HE}\right)$ is greater in the fly ashes produced by coal combustion in air than by oxy-combustion. $41 \%$ of the $\mathrm{Hg}^{2+}$ is obtained with CTP, compared to percentages ranging from 19 to $34 \%$ with CTCIE and CTCIU (Figure 6). These results agree with the mechanism proposed by Gale et al. $^{35}$ in their study on fly ashes from coal combustion in air. They observed that for moderate concentrations of unburned carbon content (i.e., around $4.0 \%$ in the ash) and when there is a shortage of calcium, as in CTP (Table 2), $\mathrm{Hg}^{0}$ might be adsorbed onto chlorinated-carbon sites, desorbing as oxidized mercury. This results in high levels of $\mathrm{Hg}^{2+}$ and low levels of mercury capture. However, for high concentrations of LOI, as in CTCIE (27.5\%), mercury adsorption is independent of the calcium concentration. Indeed, CTCIE presents the highest mercury 
retention capacity in the oxy-combustion atmosphere with a calcium content (expressed as $\mathrm{CaO}$ ) of $5 \%$ (Table 2). The CTCIU fly ashes with LOI values and calcium contents of around $14 \%$ and $20 \%$, respectively, show percentages of mercury oxidation similar to those of CTCIE but a lower mercury capture (Figure 6). Nevertheless, with the exception of CTCIE, hardly any mercury is retained in oxy-combustion conditions. The mercury retention capacities of all the fly ashes in oxy-combustion are lower than in the $\mathrm{N}_{2}$ atmosphere. The capture of $\mathrm{Hg}^{2+}$ in these cases is possibly limited by the kinetics of $\mathrm{Hg}^{2+}$ chemisorption on the ashes and /or the availability of $\mathrm{Hg}^{2+}$ sorption sites. The presence of vapour water may reduce the number of active sites on the surface of the fly ashes available for $\mathrm{Hg}^{2+}$ adsorption. However, for high concentrations of unburned carbon content (i.e. up to about 14\%), as in CTCIE, mercury retention occurs even in the presence of $\mathrm{H}_{2} \mathrm{O}$. A possible mechanism for mercury retention is the reaction of mercury with chlorinated-carbon sites located on the surface of ash particles. ${ }^{35}$ This chlorinated-carbon could be a consequence of the presence of chlorine in the flue gas or of the chlorine present in the fly ashes associated to organic matter. ${ }^{36-37}$

Figure 7 shows the HgTPD profiles corresponding to the desorption of mercury from the fly ashes in the oxy-combustion atmosphere. The desorption profile of CTP after the test carried out in the oxy-combustion atmosphere is similar to the profile of the raw CTP (Figure 2a), the main mercury species being Hg-OM and HgS. The peak corresponding to $\mathrm{HgSO}_{4}$ in the raw CTP disappears in the oxy-combustion atmosphere. This atmosphere possibly dissolves the $\mathrm{HgSO}_{4}$ as a result of the formation of $\mathrm{H}_{2} \mathrm{SO}_{4}$ at a temperature of $150^{\circ} \mathrm{C}{ }^{27}$ The profiles for mercury desorption corresponding to the CTCIU fly ashes show only one small peak at around $200^{\circ} \mathrm{C}$ due to their low mercury retention capacity. However, CTCIE, in addition to the Hg-OM species, presents a broadening of the peak between 250 and $450^{\circ} \mathrm{C}$ which could correspond to the 
decomposition of HgS red and/or mercury nitrates. ${ }^{28}$ The reactions between the NOx species present in the gas composition and the $\mathrm{Hg}^{0}$ in gas phase could give rise to different mercury nitrates which would then condense on fly ashes with a large enough surface area. The HgTPD analysis of F3, i.e. after the extraction of F1 (inorganic mercury compounds such as mercury nitrates and mercury chloride which are soluble in this fraction) and $\mathrm{F} 2\left(\mathrm{Hg}^{2+}\right.$ complexes such as $\left.\mathrm{Hg}-\mathrm{OM}\right)$ (Figure 8) reveal i) the formation of $\mathrm{Hg}-\mathrm{OM}$ and not $\mathrm{HgS}$ black because the peak at $200^{\circ} \mathrm{C}$ has disappeared and ii) that the broad peak between $200-450^{\circ} \mathrm{C}$ correspond to $\mathrm{HgS}$ red (maximum peak at $300^{\circ} \mathrm{C}$ ) and not to mercury nitrates.

\section{Conclusions}

The HgTPD analysis performed in this work has confirmed that the main mechanism for mercury retention in fly ashes occurs via the carbon matter. The main mercury species identified in the fly ashes obtained from coal combustion in air and oxy-combustion conditions are mercury bound to organic matter and HgS, the ratio of these species depending on the type of fly ashes.

From the results of the mercury experiments it can be inferred that fly ashes are the channel via which mercury oxidation in an atmosphere of oxy-combustion occurs but these hardly retain any mercury at all unless the unburned carbon content is high. The HgTPD analysis and the mercury tests show that mercury capture on fly ashes occurs via the oxidation of mercury and its subsequent adsorption onto the carbon surface, the exact retention/oxidation ratio depending predominantly on the unburned carbon and calcium content and the presence of chlorine in the flue gas and fly ashes.

\section{Acknowledgments}


The financial support for this work was provided by the National Research Program under project CTM2011-22921. The authors thank CIEMAT (Department of Energy) and CIUDEN for supplying the fly ashes employed in this study, PCTI Asturias for awarding Ms. Nuria Fernandez-Miranda a pre-doctoral fellowship and the Spanish Research Council (CSIC) for awarding Ms. Marta Rumayor a JAE-predoc fellowship.

\section{References}

(1) United Nations Environment Programme (UNEP) Mercury: Time to act, 44pp, available in http://www.unep.org

(2) Hower, J. C.; Senior, C. L.; Suuberg, E. M.; Hurt, R. H.; Wilcox, J. L.; Olson, E. S. Prog. Energ. Combust. 2010, 36, 510-529.

(3) Hassett, D. J.; Eylands, K. E. Fuel 1999, 78, 243-248.

(4) Kostova, I.; Vassileva, C.; Dai, S.; Hower, J. C.; Apostolova, D. Int. J. Coal Geol. 2013, 116-117, 227-235.

(5) López-Antón, M. A.; Díaz-Somoano, M.; Martínez-Tarazona, M. R. Ind. Eng. Chem. Res. 2007, 46, 927-931.

(6) López-Antón, M. A.; Díaz-Somoano, M.; Martínez-Tarazona, M. R. Energy Fuel. 2007, 21, 99-103.

(7) Goodarzi, F.; Hower, J. C. Fuel 2008, 87, 1949-1957.

(8) Hutson, N.D. Water Air Soil Pullut: Focus 2008, 8, 323-331.

(9) Dunham, G. E.; DeWall, R. A.; Senior, C. L. Fuel Process. Technol. 2003, 82, $197-$ 213.

(10) Senior, C. L.; Johnson, S. A. Energy Fuel. 2005, 19, 859-863.

(11) Abad-Valle, P.; Lopez-Anton, M. A.; Diaz-Somoano, M.; Martinez-Tarazona, M. R. Chem. Eng. J. 2011, 174, 86-92. 
(12) Serre, S. D.; Silcox, G. D. Ind. Eng. Chem. Res. 2000, 39, 1723-1730.

(13) Hower, J. C.; Maroto-Valer, M. M.; Taulbee, D.N.; Sakulpitakphon, T. Energy Fuel. 2000, 14, 224-226.

(14) Li, S.; Cheng, C-M.; Chen, B.; Cao, Y.; Vervynckt, J.; Adebambo, A.; Pan, W-P. Energy Fuel. 2007, 21, 3292-3299.

(15) Kostova, I. J.; Hower, J. C.; Mastalerz, M.; Vassilev, S. V. Appl. Geochem. 2011, 26, 18-27.

(16) Butz, J.; Albiston, J. Use of fly ash fractions from western coals for mercury removal from flue gas streams, in: Proceedings of the Air Quality II: Mercury, Trace elements, and Particulate Matter Conference, McLean, VA, Sept. 19-21, 2000, Paper A4-5.

(17) Hower, J. C.; Sakulpitakphon, T.; Trimble, A. S.; Thomas, G. A.; Schram, W. H. Energy Sources Part A 2006, 28, 79-95.

(18) López-Antón, M. A.; Perry, R.; Abad-Valle, P.; Díaz-Somoano, M.; MartínezTarazona, M. R.; Maroto-Valer, M. M. Fuel Process. Technol. 2011, 92, 707-711.

(19) Lei, C.; Yufeng, D.; Yuqun, Z.; Liguo, Y.; Liang, Z.; Xianghua, Y.; Qiang, Y.; Yiman, J.; Xuchang, X. Fuel 2007, 86, 603-610.

(20) Wang, Y-J.; Duan, Y-F.; Yang, L-G.; Jiang, Y-M.; Wu, C-J.; Wang, Q.; Yang, XH. J. Fuel Chem. Technol. 2008, 36, 23-29.

(21) López-Antón, M. A.; Abad-Valle, P.; Díaz-Somoano, M.; Suárez-Ruiz, I.; Martínez-Tarazona, M. R. Fuel 2009, 88, 1194-1200.

(22) Norton, G. A.; Yang, H.; Brown, R. C.; Laudal, D. L.; Dunham, G. E.; Erjavec, J. Fuel 2003, 82, 107-116. 
(23) Abad-Valle, P.; Lopez-Anton, M. A.; Diaz-Somoano, M.; Juan, R.; Rubio, B.; Garcia, J. R.; Khainakov, S. A.; Martínez-Tarazona, M. R. Fuel 2011, 190, 28082811.

(24) Huggins, F. E.; Yap, N.; Huffman, G. P.; Senior, C. L. Fuel Process. Technol. 2003, 82, 167-196.

(25) Presto, A. A.; Granite, E. J. Environ. Sci. Technol. 2006, 40, 5601-5609.

(26) Fuente-Cuesta, A.; Díaz-Somoano, M.; Lopez-Anton, M. A.; Martinez-Tarazona, M. R. Fuel 2014, 122, 218-222.

(27) Fernández-Miranda, N.; Lopez-Anton, M. A.; Díaz-Somoano, M.; MartinezTarazona, M. R. Environ. Sci. Technol. 2014, 48, 7164-7170.

(28) Rumayor, M.; Diaz-Somoano, M.; Lopez-Anton, M. A.; Martinez-Tarazona, M. R. Talanta 2013, 114, 318-322.

(29) Rumayor, M.; Díaz-Somoano, M.; López-Antón, M. A.; Martínez-Tarazona, M. R. Chemosphere 2015, 119, 459-465.

(30) López-Antón, M. A.; Yuan, Y.; Perry, R.; Maroto-Valer, M. M. Fuel 2010, 89, 629-634.

(31) Terzano, R.; Santoro, A.; Spagnuolo, M.; Vekemans, B.; Medici, L.; Janssens, K.; Gottlicher, J.; Denecke, M. A.; Mangold, S.; Ruggiero, P. Environ. Pollut. 2010, 158, 2702-2709.

(32) Yudovich, Y. E.; Ketris, M. P. Int. J. Coal Geol. 2005, 62, 107-134.

(33) Kizil’shtein, L. Y.; Peretyat`ko, A. G.; Gofen, G. I. Khim. Tverd. Topl. (Chem. Solid Fuels) 1989, 23, 132-138.

(34) Sporl, R.; Belo, L.; Shah, K.; Stanger, R.; Giniyatullin, R.; Maier, J.; Wall, T.; Scheffknecht, G. Energy Fuel. 2014, 28, 123-135.

(35) Gale, T. K.; Lani, B. W.; Offen, G. R. Fuel Process. Technol. 2008, 89, 139-151. 
(36) Martinez-Tarazona, M. R.; Palacios, J. M.; Cardin, J. M. Fuel 1988, 67, 16241628.

(37) Jimenez, A.; Martinez-Tarazona, M. R.; Suárez-Ruiz, I. Fuel 1999, 78, 1559-1565. 
Table 1. Combustion parameters for the three sampled power stations.

\begin{tabular}{lllll}
\hline FLY ASH & FEED FUEL & BOILER & $\begin{array}{l}\text { COMBUSTION } \\
\text { CONDITIONS }\end{array}$ & PLANT \\
\hline CTCIU-A & Anthracite & FBC_1 & Oxy-fuel & $30 \mathrm{MW}$ \\
CTCIU-A/P & Anthracite/Petcoke (70/30) & FBC_1 & Oxy-fuel & $30 \mathrm{MW}$ \\
CTCIU-R-A/P & Anthracite/Petcoke (70/30) & FBC_1 & Oxy-fuel & $30 \mathrm{MW}$ \\
CTCIE & Sub-bituminous coal & FBC_2 & Oxy-fuel & $100 \mathrm{~kW}$ \\
CTP & Bituminous coal/ coal wastes & FBC_3 & Air & $50 \mathrm{MW}$ \\
\hline
\end{tabular}

Table 2. Chemical analysis, mercury and chorine content, unburned carbon content (LOI) and BET surface area of the fly ash samples.

\begin{tabular}{|c|c|c|c|c|c|}
\hline & CTCIU-A & CTCIU-A/P & CTCIU-R-A/P & CTCIE & CTP \\
\hline $\mathrm{Na}_{2} \mathrm{O}(\%)$ & 0.80 & 0.79 & 0.65 & 0.69 & 0.66 \\
\hline $\operatorname{MgO}(\%)$ & 2.21 & 2.26 & 2.28 & 1.30 & 1.44 \\
\hline $\mathrm{Al}_{2} \mathrm{O}_{3}(\%)$ & 20.6 & 20.9 & 18.9 & 24.9 & 22.8 \\
\hline $\mathrm{SiO}_{2}(\%)$ & 38.9 & 37.6 & 33.7 & 55.1 & 54.2 \\
\hline $\mathbf{P}_{2} \mathrm{O}_{5}(\%)$ & 0.51 & 0.41 & 0.33 & 0.01 & $<1$ \\
\hline $\mathrm{K}_{2} \mathrm{O}(\%)$ & 2.91 & 2.81 & 2.59 & 4.00 & 3.10 \\
\hline $\mathrm{CaO}(\%)$ & 17.6 & 19.0 & 24.5 & 4.80 & 6.61 \\
\hline $\mathrm{TiO}(\%)$ & 1.02 & 1.01 & 0.91 & 0.89 & $<1$ \\
\hline $\mathrm{Fe}_{2} \mathrm{O}_{3}(\%)$ & 5.82 & 5.64 & 5.36 & 5.87 & 6.21 \\
\hline $\mathrm{SO}_{3}(\%)$ & 9.56 & 9.33 & 10.6 & 2.18 & 5.32 \\
\hline $\mathrm{Cl}(\mu \mathrm{g} / \mathrm{g})$ & 253 & 309 & 201 & 5563 & 60.0 \\
\hline Hg ( $\mu g / g)$ & 2.26 & 3.16 & 1.62 & 1.14 & 1.10 \\
\hline LOI (\%) & 14.7 & 14.3 & 13.8 & 27.5 & 3.80 \\
\hline $\operatorname{BET}\left(\mathrm{m}^{2} / \mathrm{g}\right)$ & 16.6 & 12.0 & 11.5 & 38.8 & 6.70 \\
\hline
\end{tabular}




\section{Figure captions}

Figure 1. Schematic diagram of the experimental device.

Figure 2. Mercury thermal decomposition profiles of a) raw fly ashes and b) mercury standards.

Figure 3. Mercury thermal decomposition profiles of raw fly ashes and different fractions after sequential extraction for a) CTCIU and b) CTP.

Figure 4. Percentages of $\mathrm{Hgp}, \mathrm{Hg}^{0}$ and $\mathrm{Hg}^{2+}$ in the presence of different fly ashes in a $\mathrm{N}_{2}$ atmosphere.

Figure 5. Percentages of Hgp in the fly ashes in a $\mathrm{N}_{2}$ atmosphere versus a) BET surface area values and b) LOI contents.

Figure 6. Percentages of $\mathrm{Hgp}, \mathrm{Hg}^{0}$ and $\mathrm{Hg}^{2+}$ in the presence of different fly ashes in an

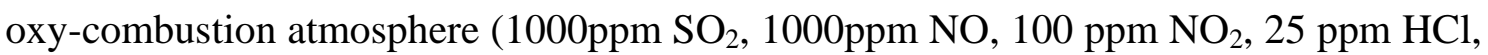
$4 \% \mathrm{O}_{2}, 12 \% \mathrm{H}_{2} \mathrm{O}, 64 \% \mathrm{CO}_{2}$ and $20 \% \mathrm{~N}_{2}$ ).

Figure 7. Mercury thermal decomposition profiles of post-retention fly ashes in the oxy-combustion atmosphere.

Figure 8. Mercury thermal decomposition profiles corresponding to CTCIE in oxycombustion and the F3 fraction after the sequential extraction of CTCIE. 


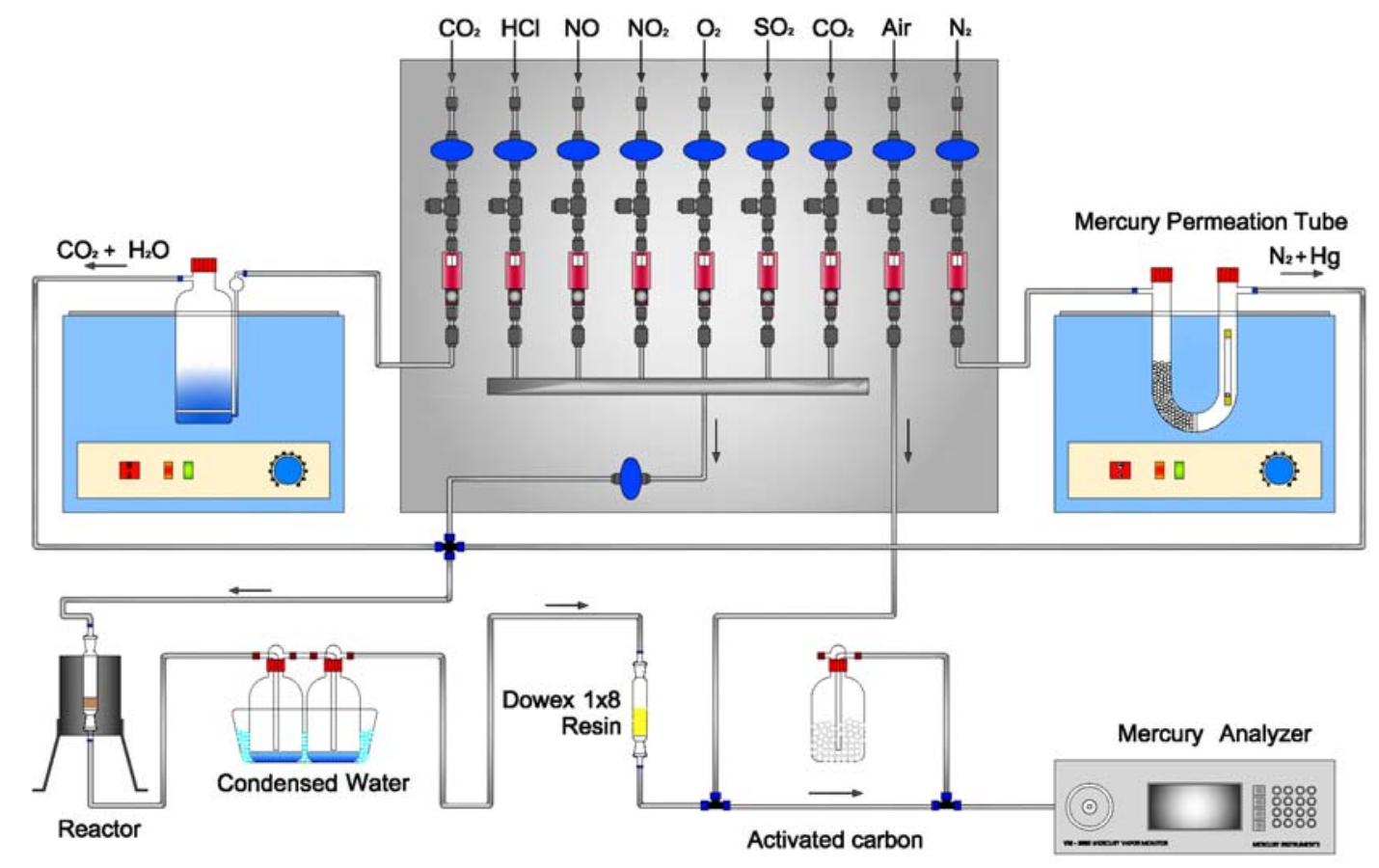

Figure 1

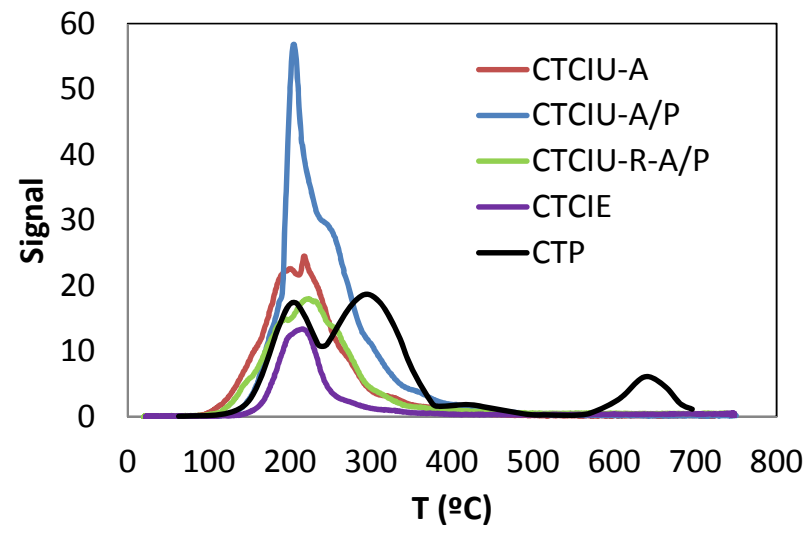

(a)

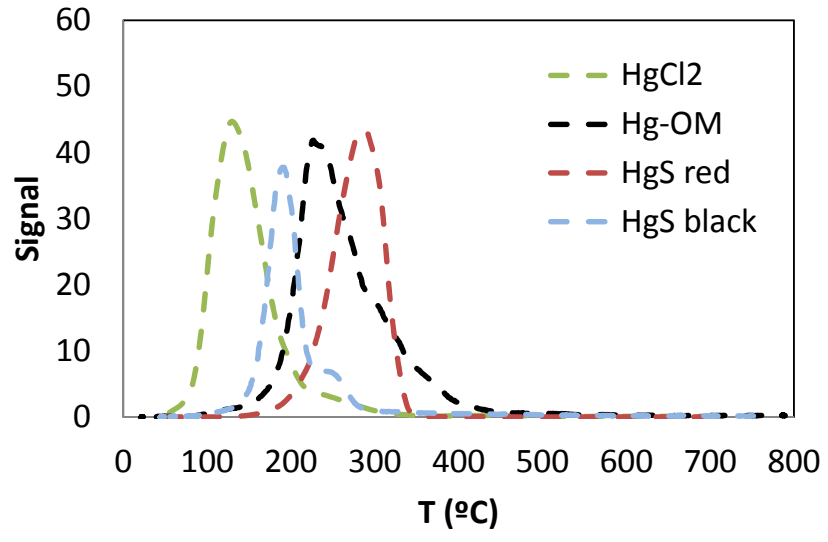

(b)

Figure 2 


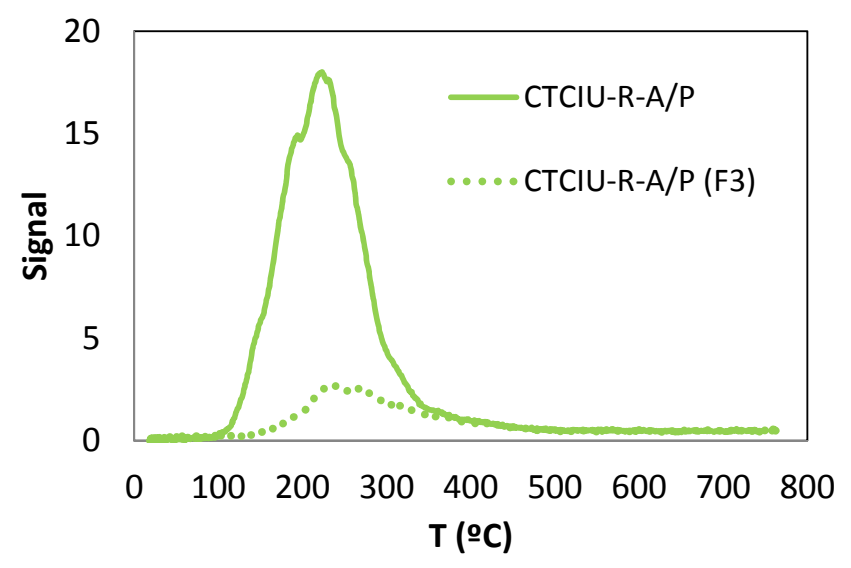

(a)

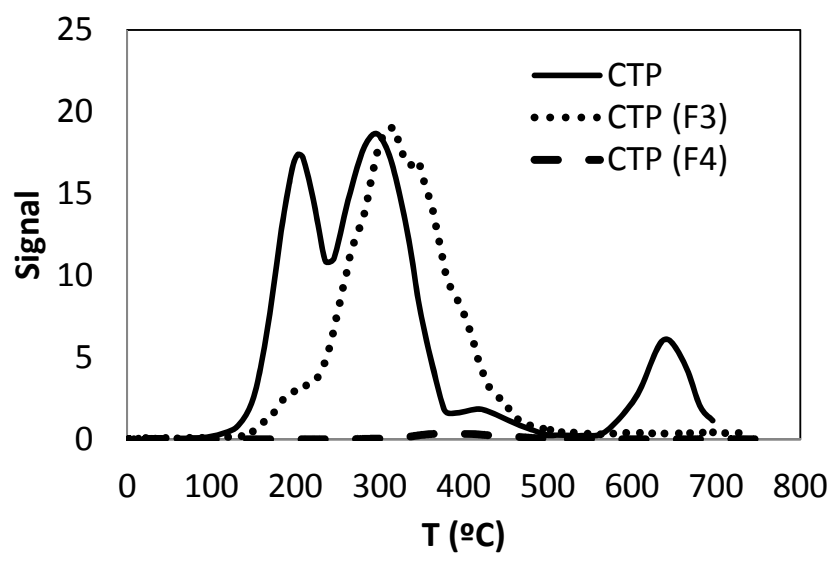

(b)

Figure 3

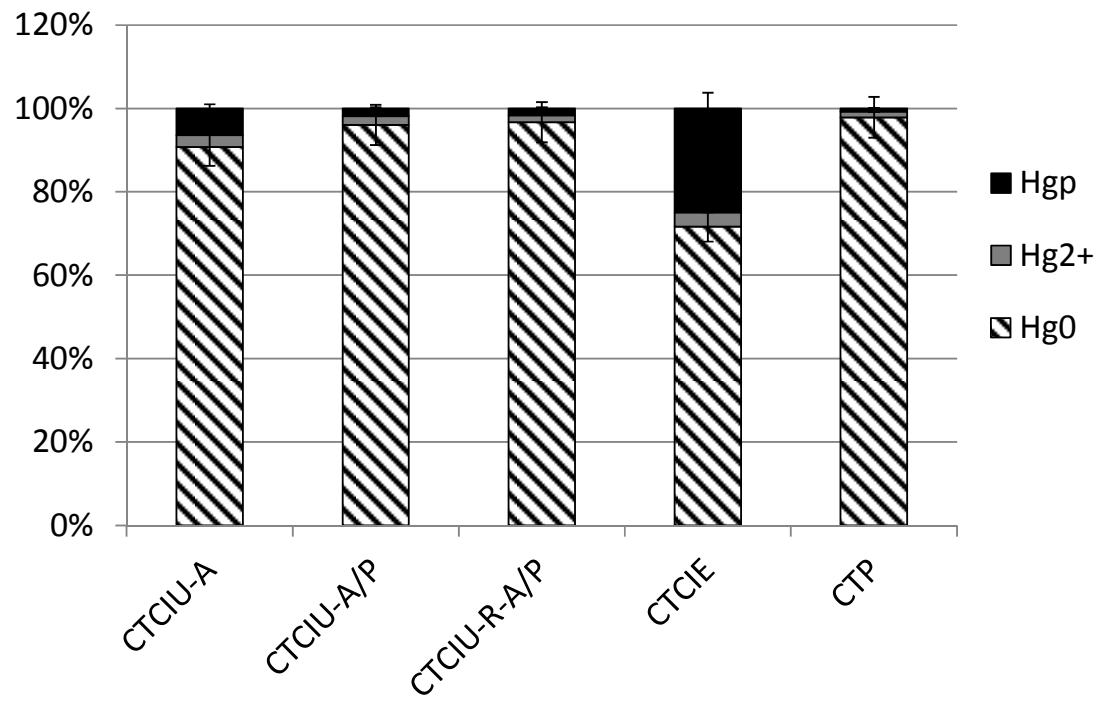

Figure 4 


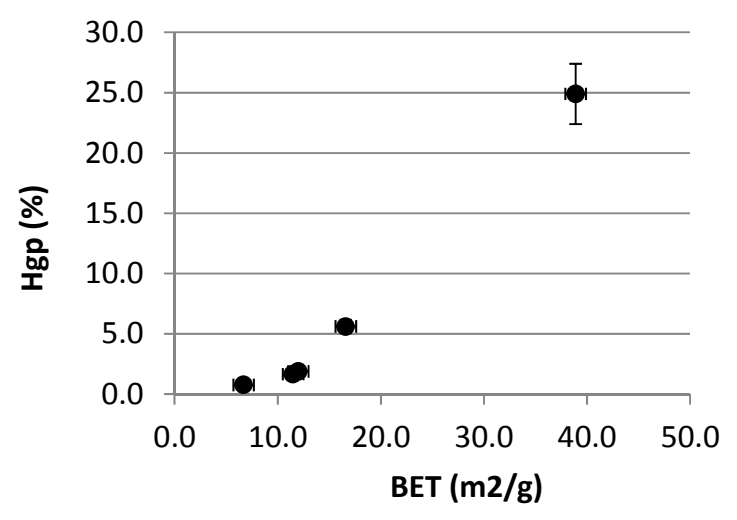

(a)

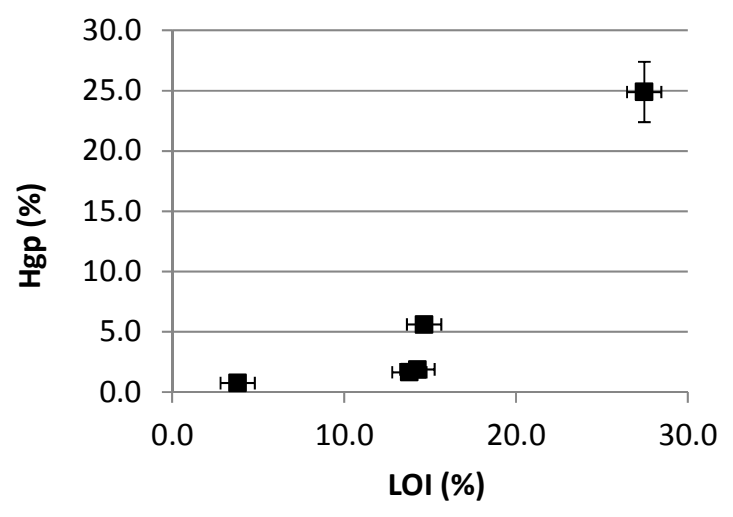

(b)

Figure 5

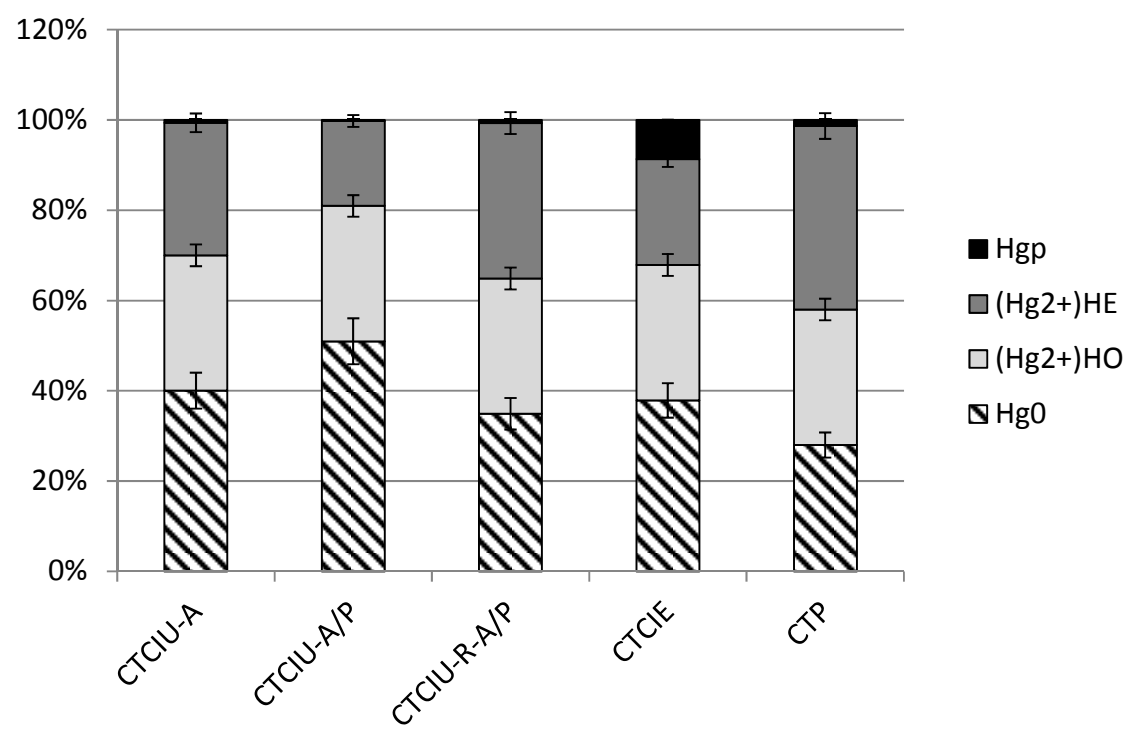

Figure 6 


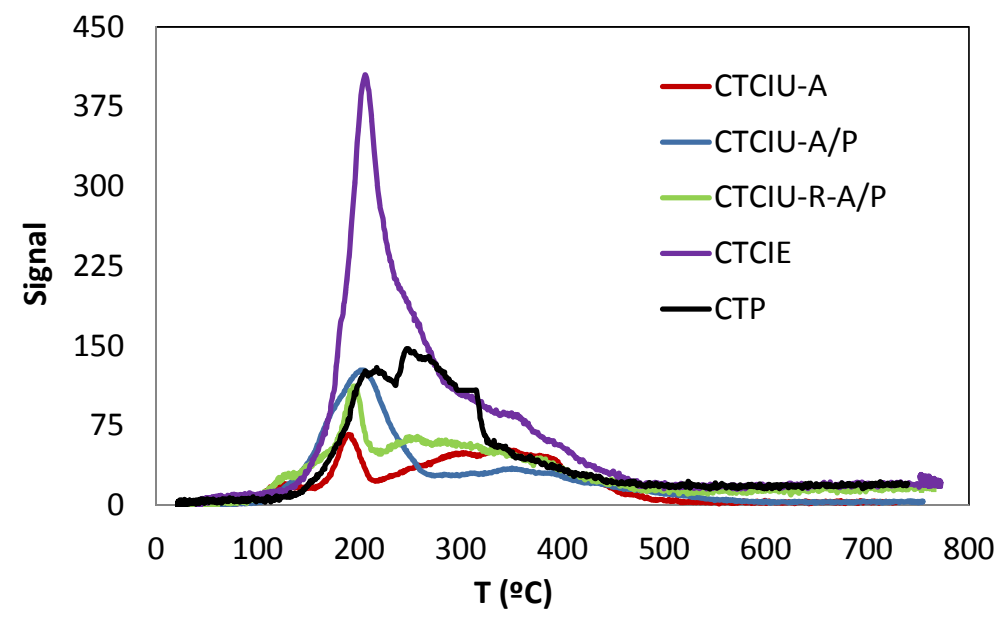

Figure 7

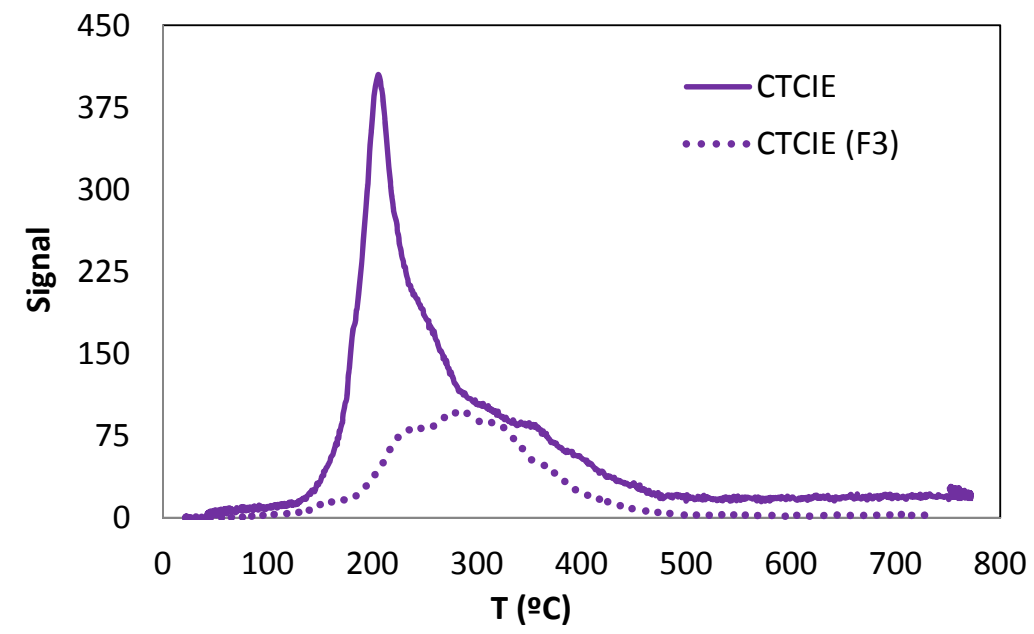

Figure 8 